\title{
A urbanização e seus impactos na densidade de drenagem e na geometria hidráulica do córrego Siriema, Jandaia do Sul-Pr
}

\author{
The urbanization and its impacts in drainage \\ density and hydraulic geometry of the Siriema \\ brook, Jandaia do Sul, state of Paraná, Brazil
}

\author{
Ederson Dias de Oliveira \\ Universidade Estadual do Centro-Oeste
}

Guilherme Aurélio Crestani Magalhães

Faculdade de Jandaia do Sul

Patrícia de Souza

Universidade Estadual de Maringá

Leandro Redin Vestena

Universidade Estadual do Centro-Oeste

\begin{abstract}
Resumo: O presente trabalho tem como objetivo avaliar os impactos do processo de urbanização em Jandaia do Sul-PR, na rede fluvial da bacia hidrográfica do córrego Siriema (BHCS). O método utilizado para verificar o ajuste da rede fluvial foi o da geometria hidráulica na direção de jusante, por meio de medições em campo das propriedades largura, profundidade, área e estimativa da descarga líquida em nível de margens plenas de 13 seções transversais do córrego Seriema. Os resultados obtidos mostraram um significativo desajuste da rede fluvial do córrego Seriema. O tipo de uso da terra como espaço urbano está presente em 38,7\% da BHCS. Os principais impactos da urbanização no sistema fluvial são alterações na morfologia dos canais fluviais e na dinâmica dos processos hidrossedimentológicos (quantidade e qualidade dos recursos hídricos). A densidade de drenagem na área urbana da BHCS é quatro vezes maior do que na rural.
\end{abstract}

Palavras-chave: Rede de drenagem. Impactos urbanos. Geomorfologia fluvial. Bacia hidrográfica.

Abstract: This study aimed to evaluate the impacts of the urbanization process in Jandaia do Sul-PR in the river network of the Siriema Brook watershed (BHCS). We have checked the river network fitness through hydraulic geometry in the downstream direction, by means of in loco measurements of properties such as width, depth, area and the discharge level estimates of net margins in 13 full cross sections. The results showed a significant disturbance of the river's network in the Siriema Brook. Urban land use is present in $38.7 \%$ of the BHSC. The main impacts of urbanization on the river system are changes in the river channels morphology and in the dynamics of the 
hydrosedimentological processes (quantity and quality of water resources). The drainage density in the BHCS urban area is four times higher than in the rural area.

Keywords: Drainage network. Urban impact. Fluvial geomorphology. Watershed.

\section{INTRODUÇÃO}

A bacia hidrográfica $(\mathrm{BH})$ tem sido amplamente utilizada como recorte espacial nos estudos geográficos, sendo que vários autores a apontam como uma unidade ambiental que possibilita tratar dos componentes e da dinâmica das interrelações necessárias ao planejamento e à gestão ambiental.

A BH é formada pelo conjunto de vertentes, drenado por um rio ou por um sistema de drenagem. Trata-se de um sistema aberto com entrada de energia (ciclo hidrológico) e exportação de matéria (água, solutos, sedimentos, etc.). Os usos do solo urbano e rural na $\mathrm{BH}$ acarretam alterações na dinâmica dos processos hidrogeomorfológicos. Entre as principais alterações ambientais estão: poluição das águas, sedimentação, erosão fluvial, mudança do regime hidrológico, do ecossistema fluvial, entre outros. (THOMAZ, 2007).

As áreas urbano-industriais referemse à mais profunda modificação humana da superfície da Terra, da atmosfera e do ecossistema terrestre. Ao contrário dos efeitos da atividade agrícola, as consequências dos impactos urbanos são altamente intensivas e localizadas. Nessas áreas, os fluxos de energia e de massa estão concentrados, sendo a maior parte da energia importada. Dessa maneira, os aspectos do ambiente são alterados pela urbanização e a industrialização, inclusive o relevo, o uso da terra, a vegetação, a fauna, a hidrologia e o clima. (DREW, 1994).

Entre os principais impactos urbanos, cabe destacar as alterações nas características morfológicas dos canais fluviais da $\mathrm{BH}$ e o aumento na densidade de drenagem. Um dos principais conceitos metodológicos que abordam os canais fluviais é a teoria da geometria hidráulica de canais fluviais, proposta por Leopold e Maddock (1953), sendo uma das primeiras aplicações de análise quantitativa em geomorfologia fluvial.

A geometria hidráulica descreve a relação entre variáveis contidas na seção transversal (vazão, profundidade média, largura do canal e área da seção transversal) que se comportam de maneira alométrica. Essas relações são representadas por variáveis geométricas definidas em dois níveis de análise: o nível de água e o nível de margens plenas.

Segundo Wolmam e Leopold (1957), o nível de margens plenas corresponde a um plano horizontal no qual a descarga líquida preenche na medida justa a seção do canal fluvial antes de ultrapassar em direção à planície de inundação. Tratase de um nível com grande significado hidrogeomorfológico, sendo possível identificá-lo em campo, pois, ao contrário do nível do fluxo fluvial, as margens plenas possuem certa "estabilidade". Dessa maneira, o nível de margens plenas delimita os processos fluviais que modelam o canal e os que constroem a planície de inundação.

As variáveis geométricas contidas na seção transversal resultam da interação de fatores relacionados à carga de detritos, suas dimensões médias, quantidade, litologia, formas deposicionais e fluxo de água; ou seja, suas dimensões não são arbitrárias. Quando as propriedades dos canais são alteradas por mudanças 
antrópicas, climáticas ou da cobertura vegetal na $\mathrm{BH}$, o sistema do canal se ajusta para um novo conjunto de condições.

Ageometriahidráulica pode ser estudada de duas maneiras: em determinada seção transversal (estações fluviométricas) ou ao longo do perfil longitudinal. A primeira prevê as mudanças na largura, profundidade e velocidade com a variação da vazão, enquanto a segunda prevê a adaptação do tamanho e da forma do canal de acordo com a variação da vazão ao longo do canal (montante-jusante). (FERGUSON, 1986).

A relação das propriedades geométricas obtidas em nível de margens plenas com a área da $\mathrm{BH}$ foi denominada por Dunne e Leopold (1978) de curvas regionais ou geometria hidráulica em nível de margens plenas.

De modo geral, o aumento da descarga num sistema fluvial equilibrado deve ser proporcional ao aumento da área de drenagem, assim como da largura e profundidade média do canal (CUNHA, 2008), ou seja, quanto maior a área de contribuição maior as propriedades geométricas da seção transversal do curso fluvial.

Os estudos de geometria hidráulica ao longo do perfil longitudinal permitem inferir o estado de ajuste dos canais fluviais. Os trabalhos envolvendo essa temática têm recebido crescente atenção por parte de vários ramos da ciência e, entre eles, cabe destacar as pesquisas envolvendo os canais fluviais urbanos, que têm sido alterados em decorrência dos impactos urbanos. Esses estudos possibilitam uma melhor compreensão dos efeitos da interferência antrópica, principalmente em áreas urbanas, nos sistemas ambientais.

A análise da geometria hidráulica na direção de jusante em nível de margens plenas é muito valiosa para engenheiros, hidrólogos, geomorfólogos e biólogos, que participam dos processos de restauração e proteção dos rios por subsidiarem ações de manejo e gestão dos recursos naturais. (DOLL et al., 2003).

O presente trabalho tem como área de estudo a bacia hidrográfica do córrego Siriema (BHCS), localizada no município de Jandaia do Sul-PR. A análise dos aspectos naturais dessa área é de grande significância, pois a malha urbana de Jandaia do Sul está se expandindo de montante para jusante na BHCS e tem potencializado alterações das variáveis físicas das duas seções, nível de água e margens plenas, além de degradação da qualidade das águas. Esses impactos são decorrentes, entre outros, da deficiência de infraestrutura (pavimentação, galerias pluviais, áreas de lazer, arborização, entre outros), poluição e contaminação das águas. Trata-se de problemas ambientais advindos de um planejamento insuficiente e do aumento do nível de pressão antrópica. Portanto, o estudo tem por finalidade avaliar o ajuste da rede fluvial e a densidade "natural" e artificial de drenagem na BHCS, diante das alterações socioambientais decorrentes do processo de urbanização da cidade de Jandaia do Sul.

\section{MATERIAIS E MÉTODOS}

\section{1 Área de estudo}

A BHCS localiza-se na região centronorte do estado do Paraná, no município de Jandaia do Sul, sendo delimitada pelos paralelos $23^{\circ} 34^{\prime} 38^{\prime \prime}$ e $23^{\circ} 36^{\prime} 10^{\prime \prime}$ de latitude Sul e os meridianos 51 $38^{\prime} 54^{\prime \prime}$ e $51^{\circ} 37^{\prime} 53^{\prime \prime}$ de longitude Oeste $(\mathrm{Gw})$ (Figura 1). 
Figura 1 - Localização da bacia hidrográfica do córrego Siriema
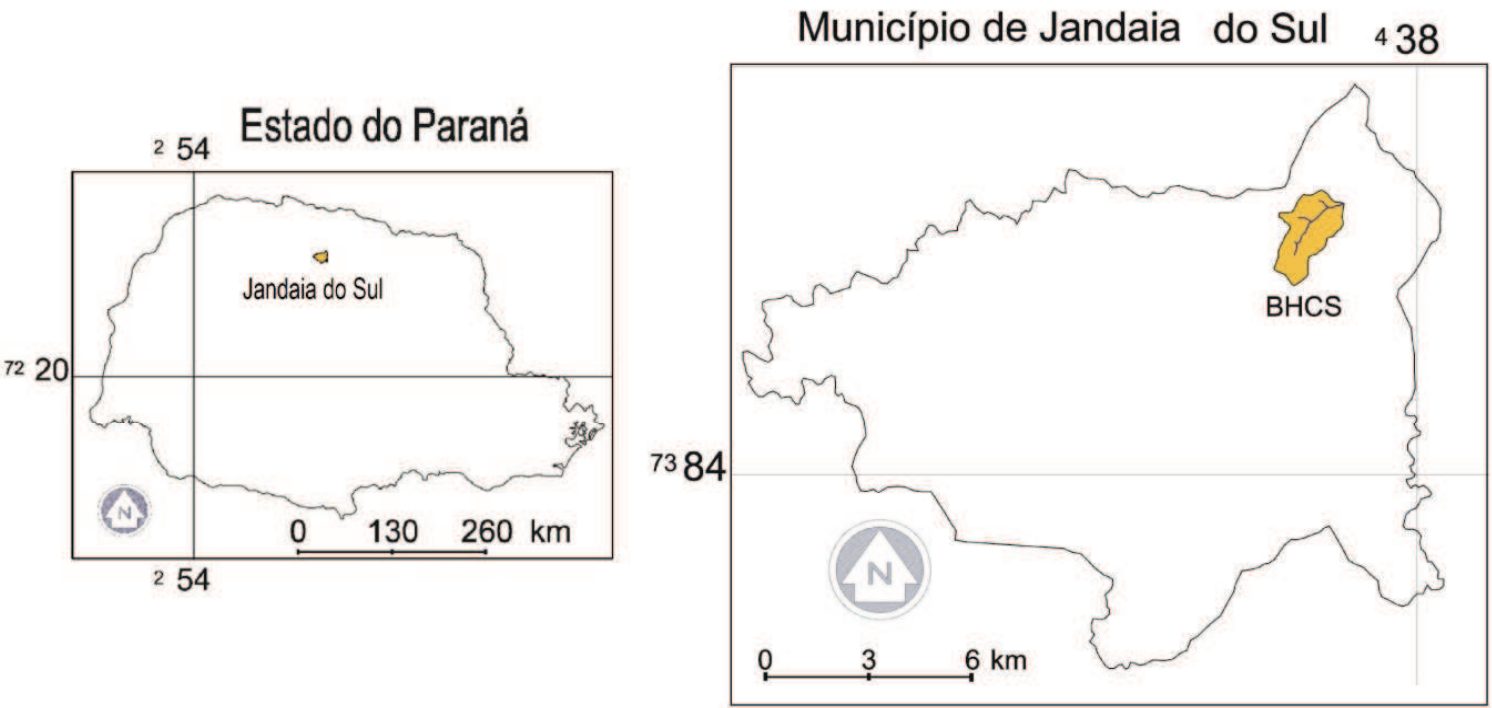

Organizado pelos autores (2010).

Base Cartográfica: Carta SF-22-Y-D-V-2 (DSG, 1980); IBGE (2007) e JANDAIA DO SUL (2006).

A BHCS ocupa uma área aproximada de $3,10 \mathrm{~km}^{2}$, tendo como canal principal o córrego Siriema, que possui um comprimento de $2,3 \mathrm{~km}$, afluente do rio Pirapó e pertencente ao sistema hidrográfico Paranapanema-Paraná. O clima na região é predominantemente subtropical mesotérmico úmido, segundo a classificação de Köppen, com média mais quente do mês superior a $22^{\circ} \mathrm{C}$ e mais fria do mês inferior a $18^{\circ} \mathrm{C}$, sem estação seca definida, verão quente e geada pouco frequente. (MAACK, 2002).

Os resquícios de vegetação nativa na BHCS expressam a ação do clima em relação à latitude, à altitude e à natureza do solo. A boa distribuição pluviométrica, em quase todos os meses do ano, contribui para o desenvolvimento da floresta Estacional Semidecidual, que se caracteriza por árvores que atingem até $30 \mathrm{~m}$ de altura, sem formar cobertura superior contínua. (MIKICH; SILVA, 2001). No entanto, atualmente são raros os locais da bacia onde subsistem remanescentes da vegetação nativa. A cobertura florestal, de modo geral, na BHCS está restrita a trechos da zona ripária e a pequenas manchas esparsas.
Quanto à base geológica, a bacia está assentada sobre o manto de rochas basálticas da Formação Serra Geral, Grupo São Bento, que se caracteriza por apresentar rochas efusivas básicas toleíticas, com basaltos maciços e amigdaloides, típicos de zonas de contato entre derrames, e de textura de afaníticos, cinzentos a pretos, raramente andesíticos, advindos de derrames de vulcanismo de fissura continental. (IBGE, 2006).

A BHCSestá inserida no Terceiro Planalto Paranaense, mais especificadamente, no Planalto de Apucarana, onde predominam declividades entre $6 \%$ e $12 \%$, topos alongados, vertentes convexas e vales em "V". (MINEROPAR, 2006). "A direção geral da morfologia é NW/SE, moderada em rochas da Formação Serra Geral". (MINEROPAR, 2006, p. 28).

Os solos predominantes no município de Jandaia do Sul são os: Neossolos pouco profundos e muito suscetíveis à erosão; Nitossolos - profundos, argilosos, bem drenados, com elevada fertilidade natural; e Latossolos - com baixa fertilidade natural, onde ocorre processo de lixiviação muito intensa, provocado pelo regime das 
chuvas. (SPVS, 1996; JANDAIA DO SUL, 2006).

O município de Jandaia do Sul possui uma população de 20.133 habitantes, segundo dados do senso do IBGE (2010), sendo que $90 \%$ desses residem na área urbana. $\mathrm{O}$ processo de urbanização na cidade é recente, ou seja, se intensificou nas últimas décadas do século $\mathrm{XX}$, assim como a expansão da malha urbana. $\mathrm{O}$ processo de urbanização deu-se de modo geral com um planejamento insuficiente, ocasionando a retirada da vegetação, a impermeabilização do solo, alterações na morfologia dos cursos fluviais e na produção e descarte de resíduos sólidos e líquidos em locais impróprios.

\subsection{Procedimentos metodológicos}

Os procedimentos metodológicos adotados foram o levantamento bibliográfico e o trabalho de campo/ gabinete:

I) Revisão bibliográfica: etapa da pesquisa na qual se buscou uma fundamentação teórica para as pretensões do trabalho, por meio de pesquisas em variadas fontes bibliográficas e cartográficas. Os materiais cartográficos utilizados foram a carta topográfica de Mandaguari, Folha SF.22-Y-D-V-3 MI2793/2, escala: 1:50.000, do DSG (Diretoria de Serviço Geográfico do Exército), do ano de 1980, e os dados contidos no Plano Diretor de Jandaia do Sul. (JANDAIA DO SUL, 2006). Os softwares utilizados foram oSPRING® 5.1.6 (Sistema de Processamento de Informações Georreferenciadas), desenvolvido pelo Instituto Nacional de Pesquisas Espaciais (INPE), e a planilha eletrônica Calc do BrOffice ${ }^{\circledR}$.

II) Trabalho de gabinete/campo: a partir da base cartográfica em ambiente SIG (Sistema de Informação Geográfica) realizou-se uma análise preliminar das propriedades morfométricas da BHCS. Essa teve como base os índices propostos nos trabalhos de Horton (1945), Chistofoletti (1980) e Oliveira et al. (2010).

Emcampoforam obtidas as propriedades geométricas de 13 seções transversais do córrego Siriema em nível de margens plenas.

A identificação e a definição do nível de margens plenas foram realizadas a partir das características morfológicas da seção transversal do canal fluvial. Essas foram definidas como o nível topográfico situado na parte superior do canal fluvial, onde é nítida a formação da planície na área adjacente a esse nível. Trata-se do nível superior do leito principal capaz de dar suporte à vazão que preenche a capacidade total do canal fluvial (Figura 2 e Quadro 1).

Figura 2 - Variáveis morfológicas de uma seção transversal.

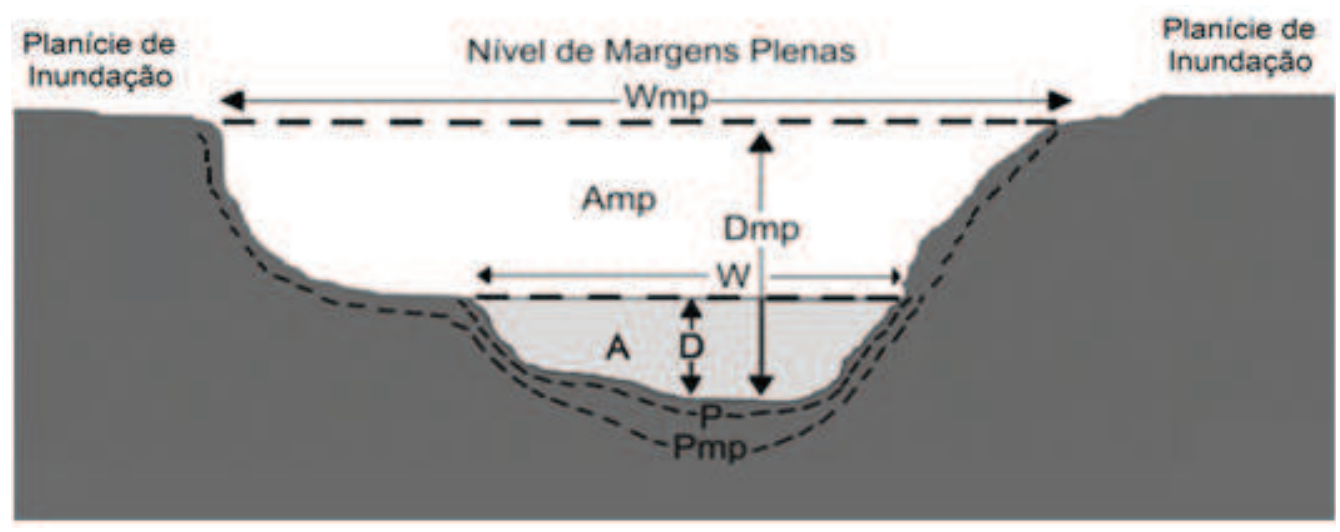

Fonte: Fernandez (2004) 
Quadro 1 - Variáveis geométricas que descrevem a morfologia de uma seção transversal

\begin{tabular}{|c|c|c|c|c|}
\hline Variável & Símbolo & Definição & Observações & Unidade \\
\hline \multicolumn{5}{|c|}{ Referência: nível d'água } \\
\hline $\begin{array}{l}\text { Largura } \\
\text { superficial }\end{array}$ & W & & Comprimento da linha horizontal da área molhada. & Metros \\
\hline $\begin{array}{l}\text { Profundidade } \\
\text { média do fluxo }\end{array}$ & $\mathbf{D}$ & $(\Sigma \mathrm{Di}) / \mathbf{n}$ & $\begin{array}{l}\text { Di são os valores da profundidade do fluxo obtidos ao } \\
\text { longo da seção transversal e } n \text { é o número de medições. }\end{array}$ & Metros \\
\hline Área molhada & A & W. D & Área da seção transversal ocupada pela água. & Metros $^{2}$ \\
\hline $\begin{array}{l}\text { Perímetro } \\
\text { molhado }\end{array}$ & $\mathbf{P}$ & & $\begin{array}{l}\text { Comprimento da linha de contato entre a superfície } \\
\text { molhada e o leito. }\end{array}$ & Metros \\
\hline Raio hidráulico & $\mathbf{R h}$ & $\mathrm{A} / \mathrm{P}$ & Quociente da área molhada pelo perímetro molhado. & Metros \\
\hline $\begin{array}{l}\text { Declividade da } \\
\text { linha de água }\end{array}$ & S & & $\begin{array}{l}\text { Declividade da linha de água no sentido longitudinal } \\
\text { em metros por metros. }\end{array}$ & Metros \\
\hline \multicolumn{5}{|c|}{ Referência: cota do nível de margens plenas } \\
\hline $\begin{array}{l}\text { Largura } \\
\text { do canal }\end{array}$ & Wmp & & Wmp é a medida em nível de margens plenas. & Metros \\
\hline $\begin{array}{l}\text { Profundidade } \\
\text { média do canal }\end{array}$ & Dmp & $(\Sigma \mathrm{Di}) / \mathrm{n}$ & $\begin{array}{l}\text { Di são os valores de profundidade do canal medidos } \\
\text { com referência ao nível de margens plenas e n é o } \\
\text { número de medições. }\end{array}$ & Metros \\
\hline $\begin{array}{l}\text { Área da seção } \\
\text { transversal }\end{array}$ & Amp & Wmp.Dmp & $\begin{array}{l}\text { Amp indica a área da seção transversal em nível de } \\
\text { margens plenas. }\end{array}$ & Metros $^{2}$ \\
\hline $\begin{array}{l}\text { Perímetro } \\
\text { do canal }\end{array}$ & Pmp & & $\begin{array}{l}\text { Comprimento do leito ao longo da seção transversal, } \\
\text { medido abaixo do nível de margens plenas. }\end{array}$ & Metros \\
\hline Raio hidráulico & Rhmp & Amp/ Pmp & $\begin{array}{l}\text { Quociente da área da seção de margens plenas pelo } \\
\text { perímetro em nível de margens plenas. }\end{array}$ & Metros \\
\hline
\end{tabular}

Fonte: Adaptado de Fernandez (2004)

Os materiais utilizados para o levantamento em campo foram: uma trena (20 m); uma régua de madeira graduada (2 $\mathrm{m})$; dois pilares de madeira amarrados por uma corda de nylon com marcas identificas a cada $20 \mathrm{~cm}$; um nível de mangueira; e um GPS (Sistema de Posicionamento Global) Garmim ${ }^{\circledR}$ de navegação, modelo GPSmap 76CSx. Os levantamentos das seções transversais foram obtidos por meio da fixação de duas estacas no solo, uma em cada margem, e interligadas por uma corda de nylon graduada a cada 20 $\mathrm{cm}$ e estendida entre as duas margens em posição horizontal e perpendicular ao leito. A declividade foi definida por meio de um nível de mangueira mensurado numa distância de 10 vezes a largura de cada seção.
As variáveis levantadas em campo nas seções mensuradas foram: a largura do canal (Wmp, em metros); a profundidade média (Dmp, em metros); a área da seção transversal (Amp, em metros quadrados); o raio hidráulico ( $\mathrm{Rh}$, em metros); o comprimento do perímetro do canal (Pmp, em metros); e a declividade da linha de água $(\mathrm{m} / \mathrm{m})$. A descarga de margens plenas (Qmp), para cada seção transversal, foi estimada indiretamente por meio da fórmula de Manning. Fernandez (2003, 2004) destaca que, uma vez identificado o nível de margens plenas, a vazão correspondente pode ser estimada por meio da equação:

$$
Q m p=\frac{1}{n} \cdot A m p \cdot R h m p^{0,66} \cdot S^{0,5}
$$


Onde Amp e Rhmp correspondem à área da seção transversal $\left(\mathrm{m}^{2}\right)$ e o raio hidráulico $(\mathrm{m})$, respectivamente, ambos em nível de margens plenas. $S$ é a declividade da linha de água $(\mathrm{m} / \mathrm{m})$ e $\mathrm{n}$ é o coeficiente de rugosidade.

Os dados das propriedades geométricas e de vazão de margens plenas, mais especificadamente da Wmp, Dmp, Amp e Qmp, foram relacionados com a área de drenagem correspondente a cada seção transversal com o auxílio da planilha eletrônica Calc do BrOffice ${ }^{\circledR}$.

A partir dos dados levantados em campo nas seções transversais foram confeccionados os perfis transversais no software Calc e calculadas as dimensões de cada variável.

Os dados referentes à identificação dos cursos fluviais canalizados foram obtidos por meio de caminhamento, com o auxílio do GPS. Os canais fluviais foram individualizados em duas classes distintas: rede fluvial "natural" e rede de drenagem "artificial". Nos primeiros foram considerados todos os cursos sem obras de engenharia ao longo da seção transversal, já os segundos foram definidos como todos os cursos alterados por obras de engenharia. Para definir essas classes foram considerados os dados contidos no Plano Diretor de Jandaia do Sul de 2006 (JANDAIA DO SUL, 2006) e da carta topográfica de Mandaguari, atualizada por meio de trabalhos de campo. Com isso, foram mapeadas a rede fluvial "natural" e a rede de drenagem "artificial". As classes de uso da terra mapeadas na BHCS foram rural e urbano. A densidade de drenagem em cada um dos diferentes tipos de uso (urbano e rural) foi estimada.

\section{RESULTADOS E DISCUSSÕES}

\subsection{Propriedades fisiográficas}

Um dos principais aspectos da $\mathrm{BH}$ é a rede de drenagem, que depende não só da pluviosidade e topografia, como também da cobertura vegetal, da litologia, do tipo de solo e da estrutura das rochas. (SUGUIO; BIGARELLA, 1990). Ao aplicar a hierarquização fluvial proposta de Strahler (1957) na BHCS, essa foi classificada como de $3^{\text {a }}$ ordem. A bacia apresenta um padrão de drenagem dendrítica que está relacionada às características do substrato rochoso que é composto, predominantemente, por derrames basálticos com resistência homogênea.

Os parâmetros morfométricos, fator de forma e coeficiente de compacidade, são os mais utilizados para verificar se a $\mathrm{BH}$ é suscetível à inundação, por influenciar no seu tempo de concentração. Para Villela e Mattos (1975), o fator de forma demonstra uma relação da bacia com um retângulo e também indica a maior ou menor probabilidade de enchentes, já o coeficiente de compacidade demonstra a proximidade da forma da $\mathrm{BH}$ com um círculo. O fator de forma da BHCS é de 0,4 , indicando que a forma da bacia, de modo geral, não favorece a concentração do fluxo fluvial, ou seja, permite que os fluxos dos tributários e encostas cheguem à exutória da bacia em tempos diferentes, com o início da chuva. Analogamente ao fator forma, o coeficiente de compacidade da bacia foi de 1,3, indicando que a forma da BHCS distancia-se da forma circular.

Os aspectos clinográficos, juntamente com a densidade da cobertura vegetal, tipo de solo, intensidade das chuvas e os aspectos antrópicos, têm fundamental influência nas taxas de escoamento superficial das águas da chuva, nos processos de erosão do solo, no assoreamento de rios e na ocorrência 
de inundações. (ROMANOVSKI, 2001). A BHCS apresenta declividades significativas em determinadas áreas, com uma mediana de $12 \%$, o que favorece a concentração dos fluxos, principalmente nas áreas de montante da bacia.

Os indicadores hipsométricos possibilitam estudar as inter-relações existentes em determinada unidade horizontal de espaço no tocante a sua distribuição em relação às faixas altitudinais, indicando a proporção ocupada por determinada isoípsa base. (CHRISTOFOLETTI, 1980). A BHCS possui uma altitude mediana de $739 \mathrm{~m}$ e altitude média de $730 \mathrm{~m}$, sendo que nos estudos hidrológicos a média pode não ser representativa do universo da pesquisa, pois pode ser influenciada por valores extremos. Assim, é usual também representar a mediana, sendo essa menos sensível a valores extremos se comparada com a média. (OLIVEIRA et al., 2010).

A amplitude topográfica da BHCS é de $150 \mathrm{~m}$, valor alcançado pela diferença da maior altitude $(809 \mathrm{~m})$ com a menor (659 $\mathrm{m})$. A definição desse índice é essencial para a caracterização da $\mathrm{BH}$, pois a amplitude do relevo influencia em parte na temperatura e na perda de água, que ocorrem pela evapotranspiração, e também na perda de volume de material da bacia (o que foi erodido) pelo entalhamento do canal.

$\mathrm{Na}$ Tabela 1 são apresentados os resultados referentes aos parâmetros morfométricos da BHCS.
Tabela 1 - Parâmetros morfométricos da BHCS

\begin{tabular}{l|l}
\hline ÍNDICES & $\begin{array}{l}\text { VALORES } \\
\text { OBTIDOS }\end{array}$ \\
\hline Área total & $3,10 \mathrm{~km}^{2}$ \\
\hline Perímetro & $8,15 \mathrm{~km}$ \\
\hline Altitude média & $730,00 \mathrm{~m}$ \\
\hline Altitude mediana & $739,00 \mathrm{~m}$ \\
\hline Declividade mediana & $12,00 \%$ \\
\hline Amplitude topográfica & $150,00 \mathrm{~m}$ \\
\hline Área rural & $1,20 \mathrm{~km}^{2}(38,70 \%)$ \\
\hline Área urbana & $1,90 \mathrm{~km}^{2}(61,30 \%)$ \\
\hline Coeficiente de compacidade & 1,30 \\
\hline Fator de Forma & 0,40 \\
\hline
\end{tabular}

Org: Autores

\subsection{Geometria hidráulica ao longo do perfil longitudinal}

Na Figura 3 é possível observar que a BHCS possui amplas áreas na parte montante com uso do solo predominantemente urbano, sendo que as áreas junto aos canais fluviais apresentam matas ripárias degradadas. O curso fluvial no setor de montante foi canalizado, estando sobreposto por arruamentos e construções. Dessa maneira, as feições morfológicas foram significativamente alteradas pelas obras setoriais realizadas pela prefeitura e moradores. $\mathrm{Na}$ BHCS os principais impactos nas propriedades morfológicas da seção transversal (leito, margens e vazão) dão indícios da remoção de material das margens e planícies adjacentes ao canal; concentração de materiais tecnogênicos nas margens e leito; tubulações artificiais para descarga das águas pluviais; canalizações em alguns trechos; vegetação ripária incipiente e leitos irregulares. 
Figura 3 - Localização e características das seções transversais na bacia hidrográfica do córrego Siriema

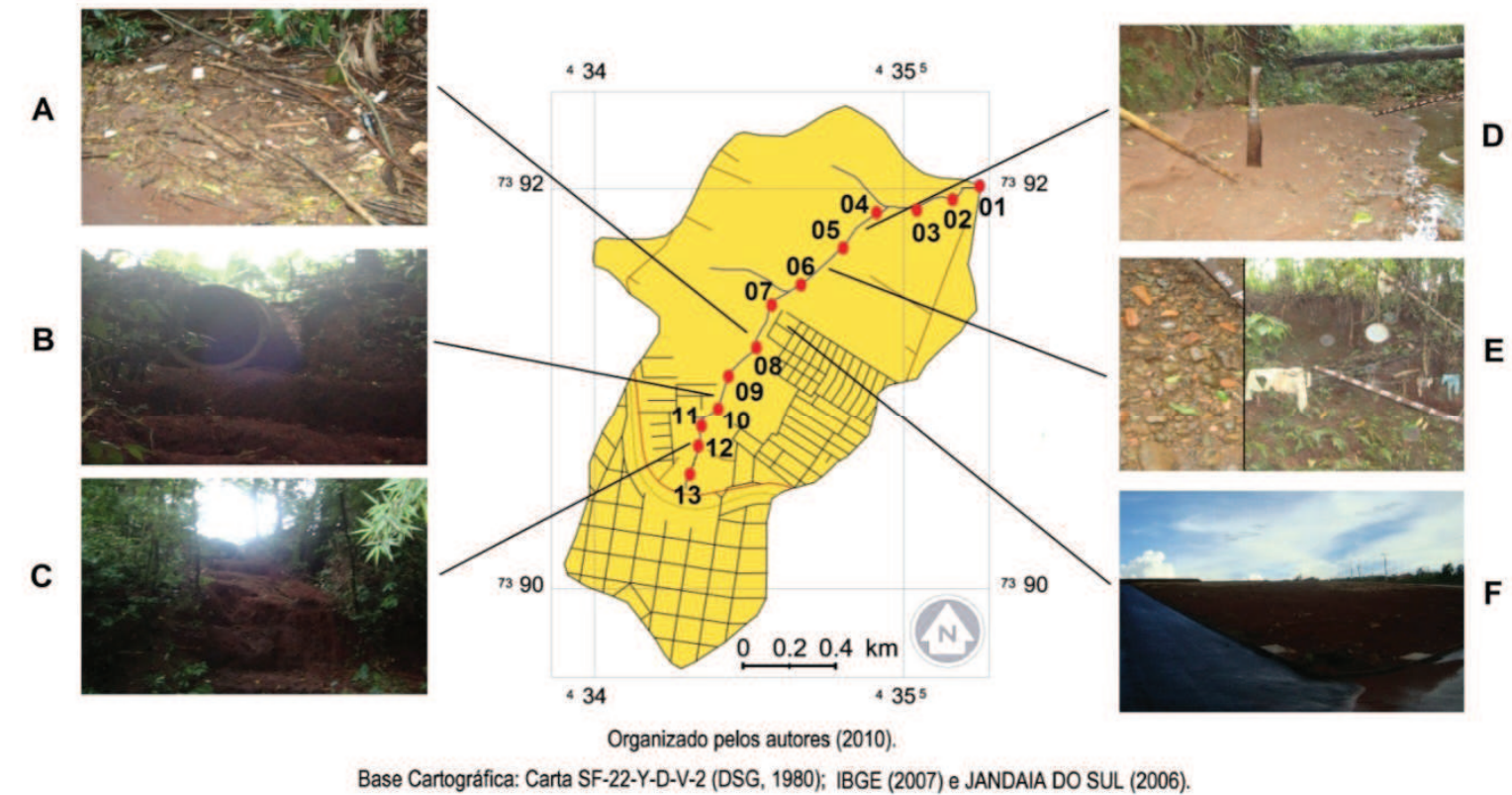

Nota: os números se referem às seções onde foram mensurados as propriedades geométricas em nivel de margens plenas.

$\mathrm{Na}$ direção de jusante, as seções transversais demonstraram não manter um aumento proporcional nas variáveis mensuradas. Com relação à área da seção transversal (capacidade do canal), os valores obtidos encontram-se entre 7,19 $\mathrm{m}^{2}$ e 16,084 $\mathrm{m}^{2}$ (Tabela 2).

Tabela 2 - Propriedades geométricas em nível de margens plenas das seções transversais do córrego Siriema

\begin{tabular}{|c|c|c|c|c|c|c|c|c|}
\hline Seção & $\begin{array}{l}\text { Coordenada } \\
\text { UTM }(X / Y)\end{array}$ & $\begin{array}{c}A \\
\left(\mathrm{~km}^{2}\right)\end{array}$ & $\begin{array}{l}\text { Qmp } \\
\left(\mathrm{m}^{3} / \mathrm{s}\right)\end{array}$ & $\begin{array}{l}\text { Amp } \\
\left(\mathrm{m}^{2}\right)\end{array}$ & $\begin{array}{l}\text { Lmp } \\
(\mathrm{m})\end{array}$ & $\begin{array}{c}\mathrm{Rmp} \\
(\mathrm{m})\end{array}$ & $\begin{array}{r}\text { Pmp } \\
(\mathrm{m})\end{array}$ & $\begin{array}{c}\text { Dmp } \\
(\mathrm{m})\end{array}$ \\
\hline 01 & $435872 / 7392017$ & 3,10 & 20,17 & 13,61 & 7,0 & 1,26 & 10,80 & 1,90 \\
\hline 02 & $435787 / 7392002$ & 3,08 & 23,85 & 14,24 & 6,8 & 1,32 & 10,80 & 2,04 \\
\hline 03 & $435697 / 7391957$ & 3,05 & 14,66 & 9,30 & 4,0 & 1,12 & 8,32 & 2,16 \\
\hline 04 & $435626 / 7391942$ & 3,03 & 6,62 & 11,68 & 6,4 & 1,26 & 9,29 & 1,72 \\
\hline 05 & $435413 / 7391901$ & 2,92 & 8,03 & 13,57 & 8,6 & 1,17 & 11,62 & 1,51 \\
\hline 06 & $435191 / 7391699$ & 2,43 & 11,79 & 15,21 & 8,8 & 1,24 & 12,20 & 1,71 \\
\hline 07 & $435069 / 7391582$ & 2,00 & 4,88 & 9,44 & 5,8 & 1,05 & 8,95 & 1,58 \\
\hline 08 & $434984 / 7391512$ & 1,90 & 16,95 & 16,84 & 9,4 & 1,30 & 12,91 & 1,76 \\
\hline 09 & $434867 / 7391437$ & 1,65 & 10,46 & 7,96 & 6,0 & 0,93 & 8,57 & 1,29 \\
\hline 10 & $434799 / 7391280$ & 1,35 & 6,78 & 10,80 & 7,0 & 1,08 & 10,00 & 1,50 \\
\hline 11 & $434673 / 7391104$ & 1,18 & 15,00 & 16,00 & 8,0 & 1,30 & 12,32 & 2,00 \\
\hline 12 & $434614 / 7390962$ & 1,04 & 4,19 & 7,19 & 4,6 & 0,96 & 7,48 & 1,44 \\
\hline 13 & $434512 / 7390721$ & 0,82 & 8,37 & 12,27 & 6,4 & 1,22 & 10,02 & 1,81 \\
\hline
\end{tabular}

Org.: Autores 
De maneira geral as seções apresentaram grandes desajustes em vários trechos, com alteração na sua morfologia, que se deve à presença de amplas áreas impermeabilizadas, favorecendo a concentração e o aumento do fluxo durante as chuvas. A largura média dos canais apresentou valores entre 4,00 $\mathrm{m}^{2}$ e 9,40 $\mathrm{m}^{2}$, com alargamentos desproporcionais na maioria das seções transversais. A profundidade média dos cursos fluviais variou entre 1,44 m e 2,16 m, com ajustes da geometria hidráulica alterados na maior parte das seções (Tabela 2).

Os dados referentes à vazão estimada em nível de margens plenas variaram entre $4,19 \mathrm{~m}^{3} / \mathrm{s}$ e $23,85 \mathrm{~m}^{3} / \mathrm{s}$ (Tabela 2). Assim como as propriedades geométricas, largura, profundidade e área da seção apresentaram inconformidades nos valores no sentido de montante para jusante nas seções mensuradas. A vazão também demonstrou desajustes dos canais fluviais.

A Figura 4 apresenta os gráficos de dispersão, relacionando a área da seção transversal, largura e profundidade média da seção em nível de margens plenas com a área de contribuição referente a cada seção mensurada.

O coeficiente de relação $\left(r^{2}\right)$, obtido entre a área da seção transversal e a área de drenagem, foi positivo, mas com um valor baixo, de $r^{2}=0,039$, demonstrando desajuste da rede fluvial. Num canal em ajuste, as áreas das seções transversais devem aumentar gradativamente de montante para a jusante e, como mostra os resultados (Figura 4), as capacidades dos canais se destoaram da linha de tendência, demonstrando, portanto, desajuste no canal nas suas propriedades geométricas.

Com relação à variável profundidade média dos canais, ainda que o coeficiente de determinação tenha sido positivo - com $r^{2}=0,147-$, esse apresentou considerável desajuste. Como se pode verificar nas fotos
C e D da Figura 03, leitos assoreados e com margens alteradas por obras setoriais realizadas ao longo das margens alteram a geometria da seção, abaixando e/ou soerguendo a planície adjacente ao canal em relação ao leito fluvial.

Os parâmetros geométricos respondem de maneira diferenciada aos impactos da urbanização. Com relação à largura média dos canais, esses apresentaram o coeficiente de relação com baixíssimo ajuste, com um $\mathrm{r}^{2}=0,002$.

A vazão também apresentou baixa correlação com o coeficiente de relação $\mathrm{r}^{2}=0,204$, demonstrando desajuste nas seções. A vazão é uma das variáveis mais nítidas à população e aos impactos nos canais, pois situações como a diminuição da rugosidade, retificação/canalização, impermeabilização e retirada da vegetação favorecem o aumento da velocidade do fluxo e o acréscimo da vazão em eventos de chuva.

Por meio dos levantamentos de campo ficou evidente que a urbanização tem contribuído significativamente nos impactos da morfologia dos canais fluviais, sendo observados vários trechos com as propriedades geométricas da seção transversal desajustadas. As variáveis das seções estão alteradas com desajustes na largura dos canais; na área da seção transversal; na profundidade média dos canais e na vazão fluvial estimada em nível de margens plenas. As propriedades geométricas dos canais fluviais da área urbana apresentam baixas correlações com oscilações positivas. Na cidade de Jandaia do Sul verificaram-se pontos onde as obras de infraestrutura reduziram as propriedades geométricas, largura, profundidade e área da seção transversal fluvial de margens plenas. Essas alterações têm potencializado o extravasamento do débito dos canais nos períodos de precipitações concentradas, sendo já 
verificadas em partes da área urbana próxima ao trecho canalizado na porção montante da bacia, com a ocorrência de alagamentos em períodos de chuvas concentradas.

A partir dos resultados obtidos pode-se afirmar que aqueles canais fluviais situados mais próximos das áreas urbanizadas têm apresentado as maiores alterações em suas propriedades geométricas, especialmente onde o processo de urbanização contribui na impermeabilização do solo, reduzindo a infiltração e aumentando o escoamento superficial para os rios, implicando assim na alteração da sua morfologia, seja por concentração de águas pluviais ou por obras setoriais.

Figura 4 - Relações entre as propriedades geométricas do canal e a área de contribuição
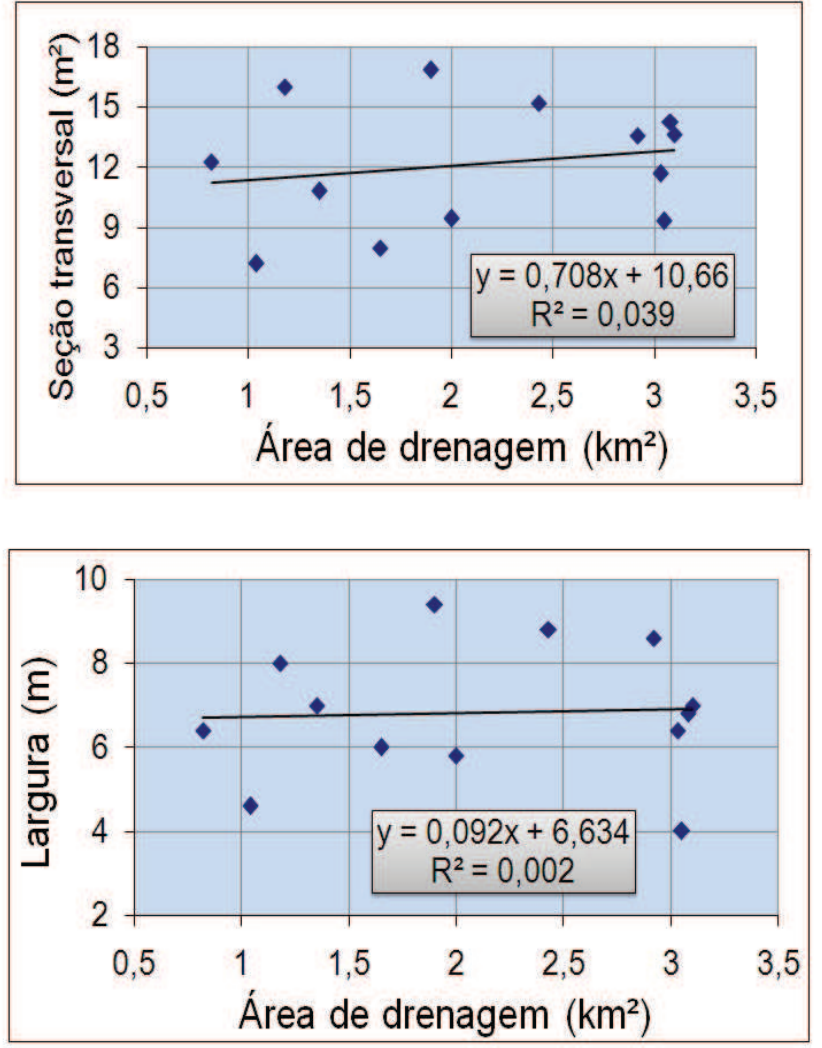

Org.: Autores

\subsection{Rede de drenagem}

Nas áreas urbanas, as edificações, o arruamento e as obras de infraestrutura de canalização e retificação de cursos fluviais, principalmente, acabam influenciando e/ ou ocasionando alterações na morfologia dos cursos fluviais. Entre as mudanças mais significativas dos canais fluviais, cabe destacar o aumento da densidade de drenagem devido à instalação de redes de drenagem artificiais nas áreas urbanas.
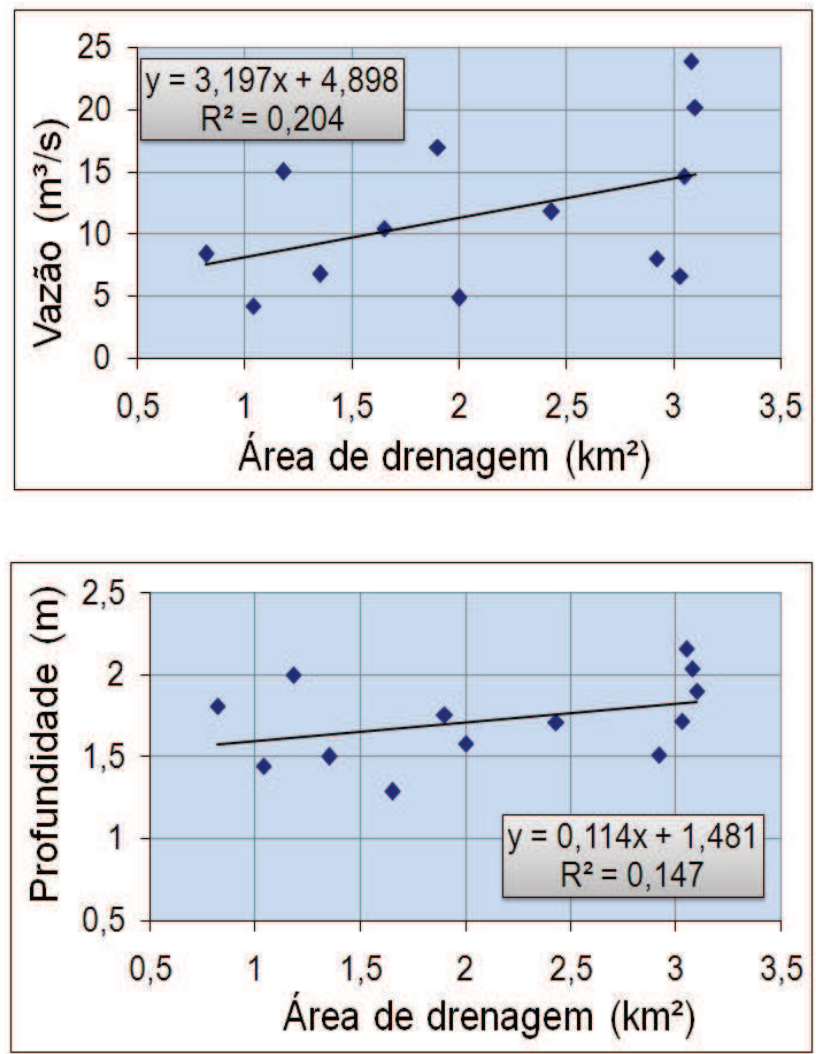

Chin (2006) menciona que os estudos em ambientes tropicais disponíveis até o momento sugerem a ocorrência de ajustes variados dos canais. Entre eles destaca-se o aumento da densidade de drenagem, resultante da implantação de redes artificiais. Isso se dá em virtude do acréscimo da concentração de água, principalmente durante as chuvas. Além do aumento do fluxo, há também acréscimo de sua velocidade, haja vista a redução da sinuosidade e rugosidade dos canais. 
No caso da BHCS, que possui uma área de $3,10 \mathrm{~km}^{2}, 1,24 \mathrm{~km}^{2}(40,0 \%)$ da mesma é ocupada pelo tipo de uso do solo urbano (Figura 5). O processo de urbanização tem se expandido na área, favorecendo a instalação de redes artificiais e a canalização de trechos do córrego Siriema.

Pelos dados apresentados no Quadro 2 é possível afirmar que a área urbana do município de Jandaia do Sul tem potencializado alterações na rede de drenagem fluvial da bacia hidrográfica do córrego Siriema. A área de drenagem rural possui $1,86 \mathrm{~km}^{2}$, com um comprimento total da rede fluvial "natural" de 3,14 km, o que dá uma densidade de drenagem de 1,69 km/ km². Com relação à área de drenagem urbana, ela possui $1,24 \mathrm{~km}^{2}$ e um comprimento total da rede de drenagem "artificial" de $8,88 \mathrm{~km}$, o que dá uma densidade de drenagem de $7,16 \mathrm{~km} / \mathrm{km}^{2}$.

Figura 5 - Rede de drenagem e tipos de uso da terra da bacia hidrográfica do Córrego Siriema

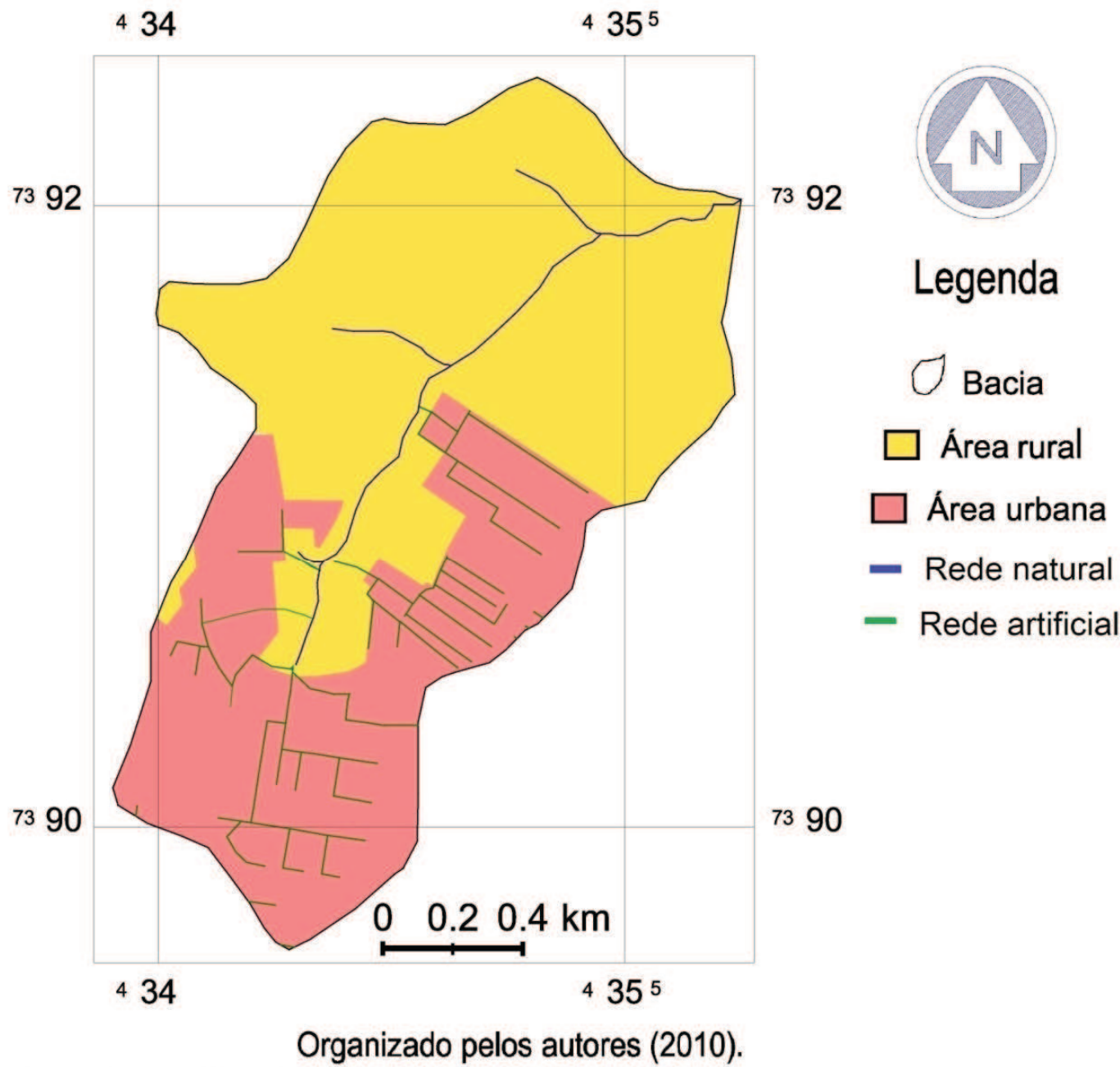

Base Cartográfica: Carta SF-22-Y-D-V-2 (DSG, 1980) e JANDAIA DO SUL (2006). 
Quadro 2 - Densidade de drenagem rural/urbano

\begin{tabular}{|c|c|c|}
\hline \multicolumn{3}{|c|}{ ÁREA RURAL } \\
\hline $\begin{array}{c}\text { Área de } \\
\text { drenagem } \\
\left(\mathrm{km}^{2}\right)\end{array}$ & $\begin{array}{l}\text { Rede fluvial } \\
\text { "natural" (km) }\end{array}$ & $\begin{array}{c}\text { Densidade de } \\
\text { drenagem }\left(\mathrm{km} / \mathrm{km}^{2}\right)\end{array}$ \\
\hline 1,86 & 3,14 & 1,69 \\
\hline \multicolumn{3}{|c|}{ ÁREA URBANA } \\
\hline $\begin{array}{c}\text { Área de } \\
\text { drenagem } \\
\left(\mathbf{k m}^{2}\right)\end{array}$ & $\begin{array}{c}\text { Rede de } \\
\text { drenagem } \\
\text { "artificial" } \\
(\mathrm{km})\end{array}$ & $\begin{array}{c}\text { Densidade de } \\
\text { drenagem }(\mathbf{k m} \\
\left.\text { km² }^{2}\right)\end{array}$ \\
\hline 1,24 & 8,88 & 7,16 \\
\hline
\end{tabular}

Org.: Autores

Os cursos fluviais classificados como "naturais" predominaram na área rural. Contudo, destaca-se que nessa área o sistema fluvial também é modificado direta e indiretamente pelas atividades agrícolas, principalmente com a retirada da vegetação para o cultivo, que intensifica os processos erosivos e o transporte de sedimentos aos cursos fluviais, bem como exige ajuste da rede fluvial. A resposta da rede fluvial às mudanças é complexa e depende da inter-relação dos diversos componentes do sistema fluvial. No entanto, em áreas urbanizadas essa complexidade pode ser ainda mais pronunciada, pois ocorre a intensificação de alguns processos em curto intervalo temporal e obras de engenharia consistentes que demandam grande quantidade de energia do sistema.

Nos trabalhos de campo podem-se notar várias tubulações que esgotam nos canais sem redutor de energia ou com baixa eficiência (fotos B e C da Figura 3).

$\mathrm{Na}$ área urbana da BHCS as redes artificiais têm uma densidade de drenagem quatro vezes maior do que nas das áreas rurais, o que implica no acréscimo da velocidade da água, haja vista a redução da sinuosidade e rugosidade dos canais fluviais. Esse incremento significativo na densidade de drenagem artificial deve-se a obras de infraestrutura decorrentes do processo de urbanização, que afetam a dinâmica dos processos hidrossedimentológicos presentes na BHCS, pois, com a impermeabilização do solo ocorre a diminuição da infiltração, percolação da água e aumento do escoamento superficial. Dessa forma, torna-se necessária a implantação de canais artificiais, a fim de dar vazão ao excesso do escoamento superficial.

Além do aumento da densidade de drenagem, ocorre também o incremento de materiais tecnogênicos nos canais fluviais, resultado do descarte de resíduos sólidos e do lançamento de efluentes - tais como plásticos, resíduos de materiais de construção, vidros, borracha, materiais orgânicos, esgoto doméstico - que obstruem e alteram as propriedades das seções transversais, modificando a qualidade da água (foto E da Figura 3).

\section{CONSIDERAÇÕES FINAIS}

Na BHCS verificou-se significativo desajuste nas propriedades geométricas das seções transversais do córrego Seriema, com pronunciados impactos nos trechos próximos da área urbana do município. Grande parte do setor superior da BHCS é ocupada pela área urbana de Jandaia do Sul, que tem potencializado alterações nos processos hidrogeomorfológicos e, consequentemente, impactos na geometria dos canais e na qualidade da água.

A densidade de drenagem na área urbana da BHCS é quatro vezes maior do que a da área rural, resultante do incremento da densidade de drenagem artificial. Esse processo lança nos rios toda água acumulada das áreas impermeabilizadas, o que resulta em elevadas taxas de materiais tecnogênicos. 
Tendo em vista os impactos no sistema fluvial, sugere-se: 1) instalação de estações de monitoramento da qualidade da água e do regime fluvial, uma vez que permitem identificar os locais mais críticos quanto à poluição e observar as "respostas" imediatas nos períodos de precipitação concentradas que elevam o nível de água nos canais fluviais; 2) intervenção por parte do poder público nos trechos urbanos onde os canais estão subdimensionados, o que potencializa a ocorrência de alagamentos induzidos pela ação antrópica; 3) reconstituição das áreas marginais ocupadas, principalmente a montante, por meio da instalação de parques nas áreas ribeirinhas, com o intuito de conservar e preservar a zona ripária; 4) avaliação da rede de esgoto atual e clandestina, promovendo soluções junto aos órgãos públicos; 5) instalação, ajustes e manutenção de dissipadores de energia na rede de drenagem, a fim de minimizar os impactos da morfologia fluvial; e 6) elaboração de projetos ambientais de sensibilização da população local sobre a importância da conservação e preservação dos ambientes fluviais.

Por fim, destaca-se a importância dos estudos que avaliam o ajuste da rede fluvial e os efeitos da urbanização na dinâmica dos processos hidrossedimentológicos ao planejamento ambiental.

\section{REFERÊNCIAS}

CHIN, A. Urban transformation of river landscapes in a global context, Geomorphology, n. 79, p. 460487, 2006,

CHRISTOFOLETTI, A. Geomorfologia. 2. ed. São Paulo: Edgar Blücher, 1980.

CUNHA, S. B. Morfologia dos canais urbanos In: POLETO. C. (Org.). Ambiente e Sedimentos. Porto Alegre: ABRH, 2008. p. 329-356.

DOLL, B. A.; DOBBINS, A. D.; SPOONER, J.; CLINTON, D. R.; BIDELSPACH, D. A. Hydraulic geometry relationships for rural North Carolina coastal plain streams. NC Stream Restoration Institute, Report to N.C. Division of Water Quality, 2003. 11p.

DREW, D. Processos Interativos Homem-MeioAmbiente. 3.ed. Rio de Janeiro: Bertrand Brasil, 1994.

DUNNE, T.; LEOPOD, L. B. Water in Environmental Planning. San Francisco: W.H. Freeman, 1978.

DSG (Diretoria de Serviços Geográficos do Exército), Carta Topográfica de Mandaguari, Folha SF.22-Y-D-V-3 MI2793/2, escala: 1:50.000, 1980.

FERGUSON, R. I. Hydraulics and hydraulic geometry. Progress in Physical Geography, v. 10, p. 1-31, 1986.

FERNANDEZ, O. V. Q. Determinação do nível e da descarga de margem plena em cursos fluviais. Boletim de Geografia, Universidade Estadual de Maringá (UEM), n. 21, p. 97-109, 2003.

FERNANDEZ, O. V. Q. Relações da geometria hidráulica em nível de margens plenas nos córregos de Marechal Cândido Rondon, região oeste do Paraná, Geosul, Florianópolis, v. 19, n. 37, p. 115134, 2004.

HORTON, R. E. Erosional development of streams and their drainage basins: a hydrophysical approach to quantitative morphology. Geol.Soc. Am. Bull. v. 56, n. 3, p. 275-370, 1945.

IBGE (Instituto de Geografia e estatísticas). Dados do Censo 2010 publicados no Diário Oficial da União do dia 04/11/2010. Disponível em: <http:/ / www.censo2010. ibge.gov.br/dados_divulgados/ index.php?uf=41>. Acesso em: 9 fev. 2011.

JANDAIA DO SUL. Prefeitura Municipal. Plano Diretor Municipal de Jandaia do Sul. Jandaia do Sul: 2006.

LEOPOLD, L. B.; MADDOCK, T. The hydraulic geometry of stream channels and some physiographic implications. Washington (DC): United States Geological Survey, Professional Paper n. 252, 1953. 57 p.

MAACK, R. Geografia Física do Estado do Paraná. 3. ed. Curitiba: Banco de Desenvolvimento do Paraná, Universidade Federal do Paraná, Instituto de Biologia e Pesquisa Tecnológica, 2002.

MIKICH, S. B.; SILVA, M. S. Composição florística e fenologia das espécies zoocoricas de remanescentes de Floresta Estacional Semidecidual no centro-oeste 
do Paraná, Brasil. Acta Botânica Brasilica, Rio de Janeiro, v. 15, n. 1, p. 19-113, 2001.

MINEROPAR, Minerais do Paraná S.A. ATLAS GEOMORFOLÓGICO DO ESTADO DO PARANÁ - Escala 1:250.000. MINEROPAR, 2006.

OLIVEIRA, E. D.; CUNHA, M. C.; VESTENA, L. R. e THOMAZ, E. L. Aspectos Morfométricos da Bacia Hidrográfica do Rio Cascavel, Guarapuava - PR. In: V SIMPGEO (Simpósio Paranaense de Pós-Graduação e Pesquisa em Geografia). Anais. Curitiba: UFPR, 2010, 36-51 p.

ROMANOVSKI, Z. Morfologia e aspectos hidrológicos para fins de manejo da microbacia da Rua Nova, Viçosa-MG, para fins de manejo. Viçosa - MG, 2001. 99f. Dissertação (Mestrado) Universidade Federal de Viçosa.

SPVS - SOCIEDADE DE PROTEÇÃO DA VIDA SELVAGEM. Nossas árvores - manual para a recuperação da reserva florestal legal. Curitiba: FNMA, 1996.

STRAHLER, A. N. Quantitative analysis of watershed Geomorphology. Am. Geophys. Union Trans., v. 38, n. 6, p. 913-920, 1957.

SUGUIO, K.; BIGARELLA, J.J. Ambientes fluviais. 2. ed. Florianópolis: Ed. UFSC, 1990. 183p.

THOMAZ, E. L. Introdução ao monitoramento ambiental em cabeceira de drenagem urbanorural. In: FERREIRA, Y. N. (org.) Águas Urbanas: Memória, Gestão, Riscos e Regeneração. Londrina: Eduel, 2007.

VILLELA, S. M. MATTOS, A. Hidrologia Aplicada. São Paulo: McGraw-Hill do Brasil, 1975. 245p.

WOLMAN, M. G.; LEOPOLD, L. B. River flood plains: some observations on their formation. Washington (DC): United States Geological Survey, Professional Paper n. 282-C, 1957. 30 p.

Recebido em: 15/12/10

Aceito em: 23/03/11 